\title{
Mutação do receptor androgênico e síndrome de insensibilidade androgênica parcial em indivíduo $47, \mathrm{XXY}$
}

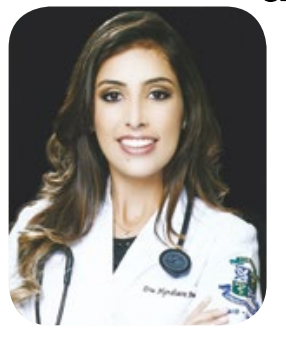

Hyndiara Frota Oliveira ${ }^{1}$ e Alina Coutinho Rodrigues Feitosa ${ }^{1}$

\begin{abstract}
Palavras-chave: síndrome de resistência a andrógenos, receptores androgênicos, síndrome de klinefelter
\end{abstract}

Key words: androgen-insensitivity syndrome, receptors androgen, klinefelter syndrome

\section{INTRODUÇÃO}

A síndrome de Klinefelter (KS) é uma das desordens cromossômicas mais comuns, sendo representada, classicamente, pelo cariótipo 47,XXY em homens. A síndrome de insensibilidade androgênica (AIS) resulta de disfunção no receptor de andrógenos (AR) em indivíduos 46XY. Na forma completa da AIS (CAIS), o paciente tem genitália externa tipicamente feminina, mas, na forma parcial da AIS (PAIS), o fenótipo é variado. Este é o primeiro relato de paciente com cariótipo 47, XXY e fenótipo de PAIS.

\section{RELATO DE CASO}

Paciente de 22 anos, com história de ambiguidade genital ao nascimento, telarca aos 15 anos, amenorreia e massas inguinais bilaterais. Ao exame físico, apresentava índice de massa corpórea de $29,8 \mathrm{~kg} / \mathrm{m}^{2}$, distribuição de gordura ginoide, desenvolvimento mamário completo, pelos pubianos escassos (escore 3 , segundo critérios de Tanner) e genitália externa com clitoromegalia $(3,5 \mathrm{~cm})$. As gonadotrofinas estavam aumentadas e a testosterona total, elevada, considerando-se a referência para o sexo feminino. Ultrassonografia pélvica não detectou útero e não havia história familiar de infertilidade, ambiguidade genital ou amenorreia primária.

O cariótipo foi $47, \mathrm{XXY}$. Devido à suspeita de AIS, foi realizado o sequenciamento do gene $A R$, que demonstrou mutação heterozigótica c.2546dupA (p.Asn849Lysfs*32). Extensa análise microssatélite do cromossomo $X$ da paciente revelou homozigose do braço curto inteiro $(\mathrm{Xq})$ e heterozigose do braço longo (exceto para um marcador $\mathrm{Xp}$ ), sugerindo isodissomia materna parcial. $\mathrm{O}$ evento de cruzamento provavelmente ocorreu no intervalo entre Xp11.22 e Xq21.1.

\section{CONCLUSÃO}

Trata-se do primeiro caso relatado compatível com Síndrome de Klinefelter com fenótipo feminino, devido associação com mutação do gene do AR, que conferiu clínica de PAIS.

\section{COMENTÁRIOS}

A síndrome de Klinefelter é a desordem mais comum dos cromossomos sexuais, acometendo $1 \mathrm{em}$ cada 600 meninos no mundo. A forma de apresentação clássica, encontrada em 80 a $90 \%$ dos casos, é associada à presença do cariótipo 47,XXY, e manifesta-se, de modo geral, com sinais de hipogonadismo, além de ginecomastia e infertilidade. Todavia, distintos fenótipos podem ser encontrados e estão associados a fatores como idade, tempo de duração da doença e alterações genéticas específicas. ${ }^{1}$

O AR faz parte de uma família de receptores nucleares essenciais para a ação dos andrógenos na formação das características sexuais masculinas primárias e secundárias. ${ }^{2}$ A síndrome de insensibilidade androgênica ocorre por mutações no AR, podendo expressar-se de forma completa (CAIS) ou parcial (PAIS). É uma doença com herança ligada ao cromossomo $X$, que afeta pacientes com cariótipo 46, XY.

Os indivíduos com a forma CAIS apresentam genitália externa tipicamente feminina, porém sem a presença dos anexos derivados do ducto de Muller. Cursam também com história de amenorreia primária e presença de massas inguinais bilaterais. A forma PAIS pode ter distintos fenótipos, que variam desde a presença de ambiguidade genital ao achado de fenótipo feminino típico com clitoromegalia e fusão parcial dos pequenos lábios. ${ }^{2} \mathrm{O}$ presente caso apresentou-se com história e achados clínicos compatíveis com PAIS.

Além dos achados clínicos, a paciente tinha concentrações de gonadotrofinas aumentadas $(\mathrm{FSH}=36$ $\mathrm{U} / \mathrm{L}, \mathrm{LH}=13 \mathrm{U} / \mathrm{L}$; referência: $1.5-12.8 \mathrm{U} / \mathrm{L}$ e $0.3-12.0$ $\mathrm{U} / \mathrm{L}$, respectivamente) e testosterona elevada ( $T=700$ $\mathrm{ng} / \mathrm{dL}$; referência em mulheres $<98 \mathrm{ng} / \mathrm{dL}$ ). Os resultados foram compatíveis com as alterações identificadas em indivíduos com insensibilidade aos andrógenos, 
em que encontram-se concentrações elevadas de LH e normais a elevadas de FSH, estrógenos e testosterona, quando comparadas às concentrações dos homens sem doença. ${ }^{3}$

A presença de mutações no gene do AR já foi identificada em pacientes com KS, previamente. ${ }^{1}$ Valente et al. estudaram uma população de 135 pacientes com KS, dos quais 8 pacientes apresentavam mutações compatíveis com insensibilidade aos andrógenos. A comparação entre os grupos, no entanto, não revelou diferenças clínicas associadas à presença de mutações previamente relacionadas à síndrome de insensibilidade androgênica. ${ }^{4}$ De forma que é relevante ressaltar que a presença de mutação não determina o fenótipo de modo isolado e que distintos mecanismos de ativação e inativação gênicas e a presença de homozigose ou heterozigose podem determinar diferentes apresentações fenotípicas. ${ }^{5}$

No presente relato, foi identificada a mutação p.Asn849Lysfs ${ }^{\star} 32$, que está associada à forma CAIS ${ }^{6}$, contudo a paciente cursou com quadro clínico compatível com a forma parcial da síndrome. A hipótese que possivelmente justifica o evento é o fato de que a presença de mutação não é o único preditor do fenótipo. ${ }^{1}$ $\mathrm{Na}$ paciente do presente caso, a ocorrência de dois cromossomos $\mathrm{X}$, devido à $\mathrm{KS}(47, \mathrm{XXY})$, pode ter levado à redução do impacto da mutação AR por mecanismos de inativação- $X$, permitindo o desenvolvimento de características compatíveis com PAIS. ${ }^{4,5}$

$\mathrm{Na}$ literatura, há descrição de dois pacientes com cariótipo 47, XXY, associado a mutações compatíveis com síndrome de insensibilidade androgênica e desenvolvimento do quadro de CAIS. ${ }^{7,8}$ Porém, não há relatos anteriores com a apresentação típica de PAIS.

Trata-se, portanto, do primeiro relato de caso de indivíduo com cariótipo 47, XXY, associado à mutação do $A R$, desenvolvendo um fenótipo equivalente à forma PAIS. O achado fenotípico incomum pode ser justificado por mecanismos gênicos variados, incluindo a inativação-X em um paciente com duplo cromossomo $X$, com a consequente atenuação da mutação do receptor, resultando em características similares à PAIS. Sugere-se que pacientes com síndrome de Klinefelter e genitália externa atípica devam ser avaliados quanto à possibilidade de AIS.

\section{REFERÊNCIAS}

1. Bonomi M, Rochira V, Pasquali D, Balercia G, Jannini EA, et al.: Klinefeltersyndrome (KS): genetics, clinical phenotype and hypogonadism. J EndocrinoIlnvest 40: 123-134 (2017).
2. Hughes, IA;Davies, JD; Bunch, TI; Pasterski, V; Mastroyannopoulou, K; MacDougall, J. Androgeninsensitivitysyndrome. Lancet 380:1419-28 (2012).

3. Melo KF, Mendonça BB, Billerbeck AE, Costa $E M$, et al.: Síndrome de Insensibilidade aos Andrógenos: Análise Clínica, Hormonal e Molecular de 33 Casos. Arq. Bras. Endocrinol. Metab 49:87-97 (2005).

4. Valente, U; Vinanzi, C; Dipresa, S; Selice, R; Menegazzo, M; lafrate, M; Foresta, C; Garolla, A. Is there any clinical relevant difference between non mosaic Klinefelter Syndrome patients with or without Androgen Receptor variations? Scientific Reports (2017).

5. Gottlieb B, Beitel LK, Nadarajah A, Paliouras M, Trifiro $M$ : The androgen receptor gene mutationsdatabase: 2012 update. HumMutat 33: 887-894 (2012).

6. Kaprova-Pleskacova, J; Stoop, H; Bruggenwirth, H; Cools, M; Wolffenbuttel, K; Drop, S; Snajderova, M; Lebl, J; Oosterhuis, J; Looijenga, L. Complete androgen insensitivity syndrome: factors influencing gonadal histology including germcell pathology. Modern Pathology 27: 721-730(2014).

7. Uehara S, Tamura M, Nata M, Kanetake J, Hashiyada $\mathrm{M}$, et al.: Complete androgeninsensitivity in a 47,XXY patient with uniparental disomy for the $X$ chromosome. Am J MedGenet 86: 107-111(1999).

8. Girardin CM, Deal C, Lemyre E, Paquette J, Lumbroso R, et al.: Molecular studiesof a patient with complete androgenin sensitivity and a 47,XXY karyotype. J Pediatr 155: 439-443 (2009).
1- Serviço de Clínica Médica do HSI
E-mail para contato:
hyndiaraf@gmail.com 